\title{
VERSLAG VAN DE CONSERVATOR OVER HET JAAR 2005
}

\section{Aanwinsten}

Aanwinsten Vereniging van Vrienden der Aziatische Kunst

- Beeld van een lohan, China $13^{\mathfrak{c}}$ eeuw, AK-MAK-1727

U Aanwinsten Rijksmuseum

- 31-delig theeservies, porselein, China, ca. 1740, AK-RAK-2005-1 t/m 31

- Stapeldoos, lakwerk, Kanton, ca. 1795, ex coll. A.E. van Braam Houckgeest, AK-RAK-2005-2

- Waaier, ivoor, Kanton, ca. 1795, ex coll. A.E. van Braam Houckgeest, AK-RAK-2005-3

- Waaier, schildpad, Kanton, ca. 1795, ex coll. A.E. van Braam Houckgeest, AK-RAK-2005-4

- Halssnoer, bloedkoraal, China, $19^{c}$ eeuw, AK-RAK-2005-5

- Achterglasschildering, portret Catharina van Braam en haar dochter,

Kanton, ca. 1795 (als bruikleen van de King Baudouin Foundation USA), AK-

C-2005-1

\section{Bruiklenen aan de tentoonstellingen}

- 'Wereld Natuur Kunst' in de Nieuwe Kerk, Amsterdam, 1 juli 2005 -

23 oktober 2005

- 'Prenten op porselein' in CODA Apeldoorn, 16 december 2005 -

19 maart 2006

\section{Restauraties}

- Spiegelstandaard, lakwerk, China, ca. 1795, AK-RAK-2003-8

- Schotel, porselein, China, 1725-1750, AK-NM-10230-B

- Bord, porselein, China, 1750-1775, AK-NM-11513-B

- Onderdelen van een servies, porselein, China, ca. 1740, AK-RAK-2005-14, $15,19,25$

\section{Publicaties van medewerkers Rijksmuseum afdeling Aziatische Kunst}

\section{Menno Fitski}

- 'Kijk op Japan', Aziatische Kunst 35/1 (2005), pp. 14-26.

- 'De Japanse theeceremonie', Vorm \& Leegte 10/3 (2005), pp. 56-59.

- [met Jan van Campen], 'Chinese monochromen in Nederland', Aziatische 
- 'Aanwinst: een sculptuur van een zittende lohan', Aziatische Kunst 35/3 (2005), pp. 22-28.

\section{Pauline Lunsingh Scheurleer}

- [met Gijs Kruijtzer], 'Camping with the Mughal Emperor. A Golkonda Artist Portrays a Dutch Ambassador in 1689', Arts of Asia 35/3 (2005), pp. 48-60.

- 'De vondsten van Muteran in Wonoboyo', in: Endang Sri Hardiati en Pieter ter Keurs, Indonesia, de ontdekking van het verleden (tent.cat. De Nieuwe Kerk), Amsterdam, 2005, pp. 52-67.

- 'Oudheidkundige vondsten op Java' Aziatische Kunst 35/4 (2005), pp. 4-13.

- 'De schat van Wonoboyo', Aziatische Kunst 35/4 (2005), pp. 14-41.

- 'Singosari-beelden in de Nieuwe Kerk', Aziatische Kunst 35/4 (2005), pp. $42-72$.

Jan van Campen

- 'Chinese bestellingen van Andreas Everardus van Braam Houckgeest', Bulletin van het Rijksmuseum 53/1 (2005), pp. 18-41.

- 'The Rijksmuseum and the collecting of Chinese ceramics in the nineteenth century', The history of collecting oriental ceramics in East and West / Vormen uit Vuur 191/192 (2005), pp. 68-79.

- " "The likeness of my mother and sister", opnieuw een aanwinst uit de collectie Van Braam Houckgeest', Aziatische Kunst 35/3 (2005), pp. 29-36.

- [Met Menno Fitski], 'Chinese monochromen in Nederland', Aziatische Kunst 35/3 (2005), pp. 2-21.

- Prenten op porselein; Chinees serviesgoed met westerse voorstellingen, Apeldoorn, 2005 (publieksbegeleiding bij gelijknamige tentoonstelling in CODA Apeldoorn)

\section{Lezingen}

\section{Menno Fitski}

- 'Bing en het verzamelen van keramiek voor de Japanse theeceremonie', Van Gogh Museum, Amsterdam, 11 februari

- 'De Japanse theeceremonie en theekeramiek', CODA Apeldoorn, 16 januari en 25 september

- 'Putting on an exhibition' Ueno Gakuen Spring School, St. Hilda's College, Oxford, 21 maart

- 'Ontmoeting' CODA Apeldoorn, 11 april

- 'Kakiemon style porcelain in the Netherlands', Fukuoka, 2 decemberfree access 
- 'Van exotisme naar esthetiek: het verzamelen van Japanse kunst rond 1900', Nederlands Genootschap voor Japanse Studieën, Leiden, 16 december

Pauline Lunsingh Scheurleer

- 'Grepen uit de Oud-Javaanse kunstgeschiedenis', Gezelligheidsvereniging de Vriendschap Amstelveen, 7 mei

Jan van Campen

- 'Van Braam Houckgeest, verzamelaar en avonturier', CODA Apeldoorn, 10 februari

- 'Schilderen op porselein', Benoordenhoutbibliotheek, Den Haag, 17 februari

- 'Een Chinese bloemenboot', Scheepvaartmuseum Sneek, 21 maart

- 'Kijken naar Chinese kunst', museumcafé CODA Apeldoorn, 26 mei

- 'Zilverdraadwerk', Geelvinck Hinloopen Huis, Amsterdam, 25 juni

- 'China-kenners en verzamelaars in de $18^{\mathrm{e}}$ eeuw', Museum Van Loon, Amsterdam, 4 oktober

- 'The Van Braam collection in the Rijksmuseum Amsterdam', CODA Apeldoorn, 22 oktober

- "'Reduced to a heap of monstruous shivers and splinters", some notes on coromandel in Europe in the $17^{\text {th }}$ and $18^{\text {th }}$ century, Victoria and Albert Museum, Londen, 11 november 